\title{
oints
}

$\sqrt{0}$

\section{Mason type 3 radial head fractures: proposal of a synthesis technique using bioabsorbable thread}

\author{
ANDREA EMILIO SALVI
}

Department of Orthopaedics and Traumatology, A.S.S.T. Franciacorta, Civil Hospital of Chiari, Brescia, Italy

\begin{abstract}
Multifragmentary fractures of the radial head (Mason type 3) are challenging for the surgeon. They are usually treated by means of complete removal of the injured head and sometimes by implantation of a metal prosthesis. Indeed, the bone fragments are often too small to allow stabilization through screws or even wires. The Author proposes an alternative technique, tested on a sawbone model, in which bioabsorbable thread is used, introduced in a figure-of-eight fashion. A review of the literature is provided.
\end{abstract}

Keywords: radial head, fracture, internal fixation, bioabsorbable, sawbone.

\section{Introduction}

Following a displaced radial head or neck fracture, excision of the radial head often gives good or fair results (1). However, the radial head is known to contribute significantly to posterolateral rotatory stability of the elbow (2). Isolated excision of the radial head has been reported to cause slight varus and external rotatory instability of 4.8 and $10.4^{\circ}$ respectively, with elbow flexion of about $40^{\circ}$ (3).

Conservative and surgical treatments have been described, in accordance with the kind of radial head fracture, mainly described and classified according to Mason (4). Whereas Mason type 1 fractures (non-displaced) can be treated easily using elbow casts, and

Corresponding Author:

Andrea Emilio Salvi, MD

Department of Orthopaedics and Traumatology

A.S.S.T. Franciacorta, Civil Hospital of Chiari

Via Cipro 30, 25124 Brescia, Italy

E-mail: andreasalvi@bresciaonline.it
Mason type 2 fractures (displaced) can be treated with screws, Mason type 3 (multifragmentary) and type 4 (involving the neck of the radial head) fractures are challenging for the surgeon. While Mason type 4 fractures are sometimes treatable by means of plate synthesis, Mason type 3 fractures are usually treated with excision of the fracture fragments and sometimes with implantation of a metallic radial head prosthesis (5). Although many prosthetic versions have been tried over the years, none of these accurately reproduces the anatomy of the proximal radius (6). Hence, in order to restore the stability of the elbow after a radial head fracture it is indispensable to save the bone fragments and to keep them reduced. For this purpose, the Author proposes a technique, tested on a sawbone model, that requires only a bioabsorbable suture thread, preferably $n^{\circ} 0$.

\section{Surgical technique}

The surgical approach can be the traditional Kocher lateral approach or an extensive Kocher lateral approach, depending on the surgeon's needs; the forearm is in neutral position, namely the position in which both the ulnar and radial styloid are vertical (7). It is essential to obtain optimal visualization of both the radial head and the zone under the radial surface located between the radial head and the biceps tuberosity. Having achieved good visualization of the fracture, the surgeon must make a channel for each bone fragment, passing a large curved needle red-hotted by mean of electrocautery, into the radial head bone, manually rotating the forearm joint at the wrist in order to visualize each fracture fragment and ending at least 5$6 \mathrm{~mm}$ under the fracture line of each bone fragment that needs synthesis (Fig. 1). It is recommended not to make more than four channels, so as to preserve as 


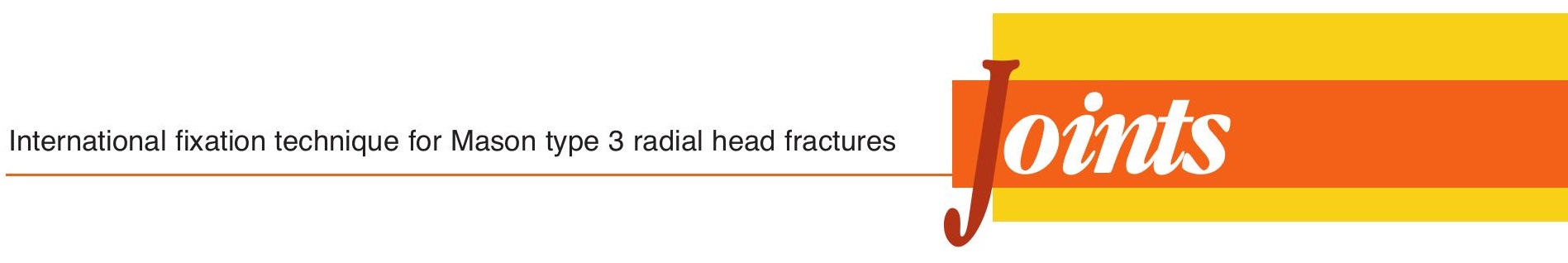

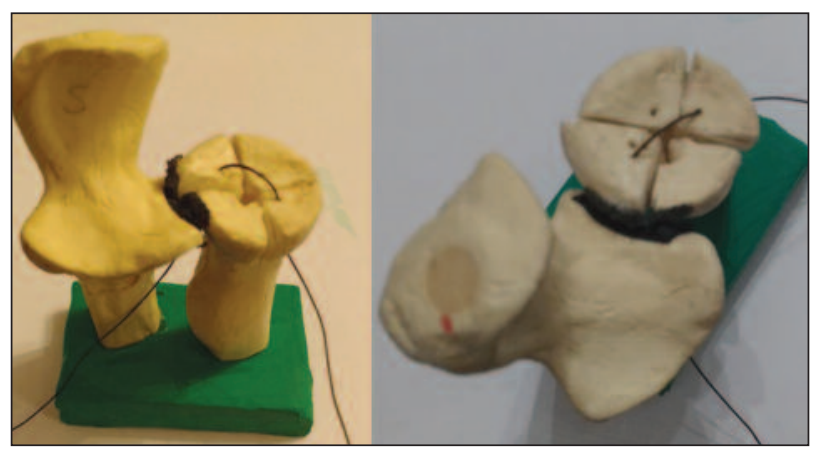

Fig. 1. A large curved needle allows the bioabsorbable $n^{\circ} 0$ thread to be introduced into the bone of the radial head as well as into the bone of the neck (5-6 mm under the line of fracture) in a cranial-caudal direction in order to avoid shifting of each fracture fragment (Sawbone model of the left proximal forearm).

much bone as possible. For this reason, it is preferable, in multifragmentary fracture cases, to make the channels in the four largest bone fragments (Fig. 2). In fact, the suture thread is applied to resemble a figure of eight in order to guarantee correct congruence of the radial head fracture fragments. To conclude the procedure, the final suture knot must be made as taut as possible so to maintain the reduction, and should preferably in an anatomical site that is easily reached (Fig. 3). It must be kept in mind that this figure-of-eight synthesis is basically a salvage technique for the treatment of radial head fractures that otherwise usually require removal of the entire radial head.

\section{Discussion}

Since the radial head is considered a crucial secondary stabilizer of the elbow in valgus and external rotation (8), its excision changes the joint kinematics, which worsen in the presence of associated lesions of medial and/or lateral collateral ligaments (9). For this reason, excision should not be performed when there are concomitant lesions, due to the risk of residual elbow instability (10). The radial column must be restored, either by means of radial head fixation or through a prosthetic solution. The latter choice is prone to significant drawbacks: pain due to overlengthening of the radius, stiffness due to metallic head oversize, and mobilization due to the stress-shielding phenomenon (11), to name but a few. These effects may be less evident in patients with low functional demands, such as the elderly, in whom metallic replacement seems to be

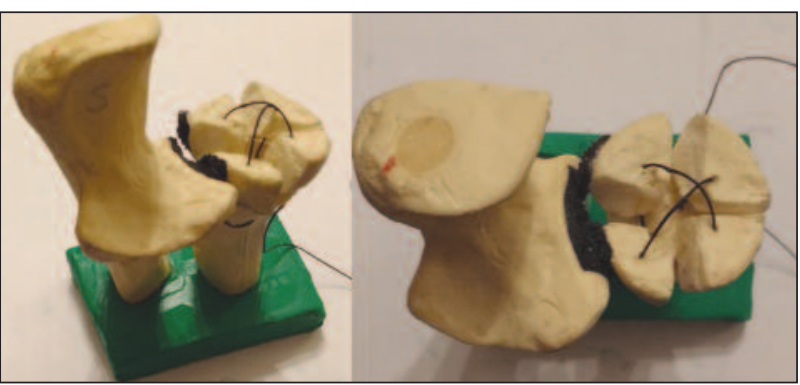

Fig. 2. A hole is made for each bone fragment. The forearm is pronated and supinated as necessary in order to improve the surgeon's visualization of each fragment and to facilitate the maneuver of visualization of each fragment and to facilitate the maneuver of
making each hole with the curved needle. The suture thread does not making each hole with the curved needle. The suture thread does not
involve the proximal radioulnar joint. Note the cross-thread on the articular surface of the radial head (Sawbone model of the left proximal forearm)

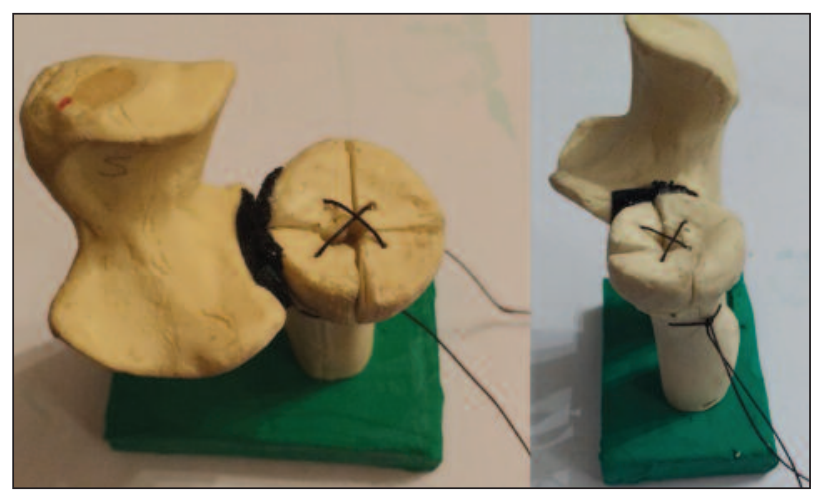

Fig. 3. Once the suture thread has been tightened, the final suture makes it possible to obtain good reduction of the bone fragments (Sawbone model of the left proximal forearm).

preferable to open reduction and internal fixation in the management of Mason 3 fractures (12).

Conversely, young patients have a high risk of revision surgery after prosthetic head implantation (13). Many artificial radial head designs have been developed, making it possible to choose between monopolar and bipolar versions (14); however, the ideal model for guaranteeing optimal tracking during movement on the capitellum remains to be established (15). Given these considerations, anatomical features of the radius are unique and very difficult to reproduce; moreover, even were a perfect prosthesis available, this should, crucially, be inserted in the correct position (6). This is the reason why it is so important to conserve the original anatomy of the radial head for as long as possible, especially when there are associated soft tissues lesions (16) and the proposed simulated technique on a sawbone model is intended to address this issue. 


\section{Joints}

\section{References}

1. Herbertsson P, Josefsson PO, Hasserius R, et al. Fractures of the radial head and neck treated with radial head excision. $J$ Bone Joint Surg Am. 2004;86-A:1925-1930.

2. Schneeberger AG, Sadowski MM, Jacob HA. Coronoid process and radial head as posterolateral rotatory stabilizers of the elbow. J Bone Joint Surg Am. 2004 Mav;86A(5):975-82.

3. Søjbjerg JO, Ovesen J, Gundorf CE. The stability of the elbow following excision of the radial head and transection of the annular ligament. An experimental study. Arch Orthop Trauma Surg. 1987;106(4):248-50.

4. Mason ML. Some observations on fractures of the head of the radius with a review of one hundred cases. Br J Surg. 1954;42:123-132.

5. Bain GI, Ashwood N, Baird R, et al. Management of Mason type-III radial head fractures with a titanium prosthesis, ligament repair, and early mobilization. Surgical technique. J Bone Joint Surg Am. 2005;87 Suppl 1:136-147.

6. Van Riet RP, Van Glabbeek F, Neale PG, et al. Anatomical considerations of the radium. Clin Anat. 2004;17:564-569.

7. Morrey BF, An KN, Stormont TJ. Force transmission through the radial head. J Bone Joint Surg Am. 1988;70:250256.

8. Laun R, Wild M, Hakimi M. One-year results of cemented bipolar radial head prostheses for comminuted radial head fractures. GMS Interdiscip Plast Reconstr Surg DGPW. 2015; 4: doi: 10.3205/iprs000071.

9. Kodde IF, Kaas L, Flipsen M, et al. Current concepts in the management of radial head fractures. World J Orthop. 2015; 6:954-960.

10. Solarino G, Vicenti G, Abate A, et al. Mason type II and III radial head fracture in patients older than 65: is there still a place for radial head resection? Aging Clin Exp Res. 2015;27 Suppl 1:S77-S83.

11. Delclaux S, Lebon J, Faraud A, et al. Complications of radial head prostheses. Int Orthop. 2015;39:907-913.

12. Liu R, Liu P, Shu H, et al. Comparison of primary radial head replacement and ORIF (open reduction and internal fixation) in Mason type III fractures: a retrospective evaluation in 72 elderly patients. Med Sci Monit. 2015;21:90-93.

13. Duckworth AD, Wickramasinghe NR, Clement ND, et al. Radial head replacement for acute complex fractures: what are the rate and risks factors for revision or removal? Clin Orthop Relat Res. 2014;472:2136-2143.

14. Hartzler RU, Morrey BF, Steinmann SP, et al. Radial head reconstruction in elbow fracture-dislocation: monopolar or bipolar prosthesis? Clin Orthop Relat Res. 2014;472:21442150.

15. Shannon HL, Deluce SR, Giles JW, et al. The effect of radial head implant shape on radiocapitellar kinematics during in vitro forearm rotation. J Shoulder Elbow Surg. 2015;24:258264.

16. Van Glabbeek F, Van Riet R, Verstreken J. Current concepts in the treatment of radial head fractures in the adult. A clinical and biomechanical approach. Acta Orthop Belg. 2001; 67:430-441. 